\title{
Women MPs and the Socio-Environmental Preconditions for Political Participation in the Federal Republic ${ }^{1}$
}

With the election of Germany's first woman chancellor in November 2005 it would appear that equal opportunities have finally been achieved in German politics. Furthermore most parties in the Federal Republic are committed to increasing or maintaining certain levels of female representation within their ranks, and many use quotas to achieve this. This article looks not only at the formal mechanisms employed by the German parties to help women enter politics, but also at whether the practice of politics is conducive to women's working methods and lifestyles. Its focus is on the compatibility of a political career with family responsibilities. The author argues that while quotas have helped increase the number of female politicians, party cultures and practices have not been completely transformed. Many problems remain for current and potential female politicians, especially those whose family circumstances make it hard to adapt to the male norms of behaviour which still characterise political life in the Federal Republic.

One of the most important areas of Eva Kolinsky's work was her research on women in contemporary Germany. Although she wrote about various aspects of German women's lives, ${ }^{2}$ she will probably be best remembered for her publications on the impact of reunification on women, ${ }^{3}$ and on the participation of women in German politics - as voters, party members and politicians. ${ }^{4} \mathrm{~A}$ key aspect on her work concerned the impact of women's quotas, first introduced by the Greens, and subsequently by other parties. ${ }^{5}$ While Professor Kolinsky accepted that the introduction of quotas had 'recast the process of nomination ${ }^{6}$ for political office, she also pointed out their shortcomings, noting in 1993 that in spite of quotas, 'democratic party cultures with wider scope for women to participate in the style that they prefer have yet to emerge'. ${ }^{7}$ Whether this is still the case today, well over a decade later, is a key theme of the following article.

\section{INTRODUCTION}

There can be no doubt that women's access to political power in the Federal Republic has improved greatly over the past two decades, ${ }^{8}$ with a substantial increase in the number of female members of the Bundestag (now 31.6 per cent), and culminating in the election of Angela Merkel as the first female federal chancellor in the Autumn of 2005. However it 
would be premature to conclude that these developments are a sign that all women now have the same opportunities as their male counterparts in German politics. As has been discussed in detail elsewhere, ${ }^{9}$ the rise of Frau Merkel can be attributed to a very specific set of circumstances, namely the discrediting of former chancellor Helmut Kohl and his closest allies in the Christian Democrats' party funding scandal (dubbed 'Kohlgate') in 1999. However, is it now just as easy for women to begin a parliamentary career and progress to positions of real power as it is for men, or is this only true for those who are able to behave like men and play by the existing rules of the political game?

The increase in the proportion of women in most German parliamentary parties is largely attributable to the introduction of women's quotas in the 1980s and 1990s (see the article by Louise K. Davidson-Schmich in this volume). In research published soon after German reunification Eva Kolinsky concluded that quotas had had both positive and negative consequences. On the positive side, the numbers of female parliamentarians had increased, and parties had 'cleared a backlog of office-seeking among long-standing members ${ }^{10}{ }^{10}$ However, on the negative side, quotas had failed to create new styles of participation or to challenge hierarchical practices: 'the focus on the quota has underscored the organisational, and overshadowed the socio-environmental preconditions for political participation'. ${ }^{11}$ In particular, Kolinsky found that the well-educated and highly qualified women the parties hoped to attract as activists were also those 'for whom the age-old questions of multiple commitments have yet to be solved', ${ }^{12}$ in other words, women already performing a delicate balancing act between their careers and family responsibilities with little spare time for politics with all the evening and weekend commitments it entails.

More than a decade after Kolinsky's findings were published, this article revisits Kolinsky's argument and considers whether women with 'multiple commitments' (specifically family responsibilities) have the same opportunities in German politics as other women and men. It considers whether motherhood is still a significant hurdle for senior office, in spite of all the rhetoric regarding the need to increase the number of female MPs by German political parties. (Angela Merkel does not have any children.) Linked to this are various other questions, including whether concerns about achieving an equitable work-life balance deter many women from entering politics in the first place, 
whether the conduct and timetable of political life discriminates against those who do enter and prevents them rising to senior positions, and whether the male dominated culture of parties and parliaments works against the introduction of more family-friendly practices. Have women finally penetrated the 'glass ceiling' in German politics, only to be confronted by a 'maternal wall'? On the other hand does 'Supermutti' ${ }^{13}$ Ursula von der Leyen, federal family minister and mother of seven, prove that female politicians can now have it all?

This article begins with a general discussion of potential problems for female politicians with families, and goes on to look at the German case, taking into account the conduct of politics at federal level and the demands on German MPs. It then outlines each of the main parties' policies to promote women, including quotas and any measures designed to make politics more compatible with women's lives. Problems common to all German women MPs with children, regardless of their party, are identified, drawing on the views of a sample of female Bundestag members obtained via interviews and questionnaires. This enables conclusions to be drawn regarding the validity of Kolinsky's arguments for German politics today.

\section{CONDITIONS FOR POLITICAL PARTICIPATION}

Early in the $21^{\text {st }}$ century the suggestion that motherhood hinders a woman's chances of a successful career in politics may seem to be rather a dated view, if not politically incorrect. Also, not all women want to have families and this is as true for politicians as for the rest of the female population. However, since the late 1980s and early 1990s feminist theorists have recognised the situational constraints on existing and potential female politicians. As Vicky Randall argues: 'Women’s responsibility for small children is perhaps the key constraint on the "supply" of women for leading political positions, determining both the age at which they become available and the qualifications they bring, ${ }^{14}$ Randall is particularly concerned that women with young children will simply not come forward for political positions due to the practical problems they anticipate in advance, ${ }^{15}$ as climbing the political ladder often leads to the 'three job problem, ${ }^{, 16}$ combining paid employment, family responsibilities and honorary political positions. 
Unfortunately, we will never know how many mothers abandon political aspirations from the outset, fearing a conflict of interest, although there have been some high profile cases of British politicians who have attempted to balance political and family life, and eventually sacrificed their political positions in order to care for their children or even elderly parents. ${ }^{17}$ Indeed, former British Prime Minister Tony Blair admitted that combining the office of prime minister with bringing up a young child had only been possible with the help of his mother-in-law. ${ }^{18}$

Other theorists have identified time constraints and the unpredictability of mothers' daily schedules as the biggest problem for women MPs with children. ${ }^{19}$ Anne Philips concurs with these views: 'Is the heart of the matter the conditions under which children are cared for and reared, so that as long as this remains the private responsibility of invisible women, there is limited time for them to invade men's political sphere? ${ }^{20}$ She alludes to ancient Athenian democracy where males were freed of domestic responsibilities by women and slaves, and were thus able to participate fully in the democratic process, ${ }^{21}$ a situation which is not so dissimilar to the lives of many male politicians today. Furthermore, 'the way our private lives are organised promotes male involvement and reduces female participation. Who collects the children and who makes the tea is a vital political concern'. ${ }^{22}$ For Phillips (and others), the key condition, if men and women are to be political equals, is 'equalising the distribution of responsibility and time in each household, ${ }^{23}$

The only solution would seem to be a social revolution, which would totally shake up gender roles in society, notably in the realms of production and reproduction, and the creation of an egalitarian utopia in which men and women have an equal share of both parenting and political power. While this may be unlikely in a country such as Germany in the immediate future, since the late 1990s successive governments have been committed to the concept of gender mainstreaming which requires consideration of the impact of policies and practices on both women and men prior to their adoption. ${ }^{24}$ Furthermore, with declining birth rates, the question of how to help women reconcile work and family commitments is a highly topical issue, highlighted by the heated debate generated by the new Elterngeld (parental allowance) introduced by Merkel's government in $2007 .{ }^{25}$ However, the political environment itself remains largely 
untouched by these developments in spite of the fact that all the main parties at least pay lip service to the idea of increasing female political representation, with most using quotas to guarantee certain levels of female representation within their ranks. But such

rules and regulations alone do not automatically create the 'critical mass ${ }^{, 6}$ of women which seems to be necessary if the conduct of party politics is to change fundamentally, unless they are complimented by other measures designed to ensure a level playing field for all, regardless of personal circumstances. Put differently, what use are quotas without crèches?

\section{THE CONDUCT OF PARLIAMENTARY BUSINESS AT FEDERAL LEVEL}

In most modern democracies the daily and weekly routines of MPs are very demanding and unpredictable, and in view of breadth of the role it is hard to see how it could become a ' 9 to 5' job. MPs have to juggle parliamentary business, constituency work and party commitments, plus additional responsibilities in the case of government ministers, which makes an equitable work-life balance a real challenge for all MPs. But parliaments do not meet every week of the year and there are benefits compared with other jobs, notably the long summer recess. The German Bundestag is scheduled to be in session for 20 weeks in 2007. It does not sit in July and August although some ad hoc committees do convene during the summer. Other breaks tend to coincide with school holidays in the larger Länder, which can cause problems for MPs with children elsewhere.

In a typical week plenary sessions are scheduled to take place Wednesday afternoons, all day and into the evening on Thursdays, and until mid-afternoon on Fridays. At other times MPs attend working parties, meetings for the whole Fraktion or for MPs from their own Land, and parliamentary committees, not to mention receptions and other evening events. ${ }^{27}$ Wednesday mornings and late afternoons are popular slots for parliamentary committees to meet, and many convene at 8 a.m. on Thursdays and Fridays, before the start of parliamentary sessions. Thus an MP's diary soon fills up with meetings even if relatively few hours are spent in the chamber, and the working day is long, hence even local MPs see little of their families during weeks when parliament is in session. However, while none would describe their work environment as family-friendly, some 
women MPs believe they have a more flexible existence than many other working mothers since they can often choose which parliamentary sessions to attend, have a certain amount of control over their own diaries, and have a good income, thereby enabling them to afford childcare and domestic assistance. ${ }^{28}$ Furthermore, the Bundestag Kindergarten, once only for the children of staff, is now open to MPs' children, although clearly this is only of benefit to those based in Berlin. However, on the negative side, MPs are technically self-employed and do not qualify for the maternity entitlements which apply to normal employees.

The weeks when the Bundestag is not in session are spent in the MP's constituency or the Land in which they are elected in the case of MPs elected via party lists. Around twothirds of female MPs are in the latter category since quotas cannot be so easily applied to constituency nominations and all of the parties select more male than female candidates for these, ${ }^{29}$ but even those elected via party lists have specific responsibilities for their party in their own Land. While the weeks spent back home are somewhat easier for MPs with families, they fill up with party events and constituency commitments, many of which take place in the evenings and at weekends. As Katherina Reiche MdB comments, in the Federal Republic MPs are expected to be permanently available, even on Sundays for a customary beer. ${ }^{30}$ One female MP claims that a 60 hour working week is not uncommon. $^{31}$

The process of working one's way up the ranks, traditionally known as the Ochsentour, ${ }^{32}$ involves regular attendance of party events, election campaigning, and volunteering for honorary roles, all of which are major time commitments. As Kolinsky noted in the early 1990s, quotas have to a certain extent helped women to side-step this process, ${ }^{33}$ but still the most hotly contested party positions are often decided among elite circles late at night in smoky pubs, even in the more progressive parties. ${ }^{34}$ Such practices exclude many women, but particularly those with family responsibilities, who cannot so easily adapt to male norms of behaviour. ${ }^{35}$ In particular, only the most high profile party members secure nominations for safe constituency seats and these tend to be men who are more likely to be able to attend extra-curricula events. Thus the problem of access to unofficial networks seems to be one of the greatest challenges for women MPs, and their continued existence, coupled with a tradition of decision-making behind closed doors, is 
a reflection of the patriarchal behaviour that still characterises inner-party culture and is not confined to the more traditional parties. ${ }^{36}$

As a result of these customs and practices an equitable work-life balance is a challenge for many politicians, especially those with family commitments. Several female German MPs believe that many women are deterred from standing for election in the first place if they have a family or are planning one, due to fears that life would be come too much of a 'juggling act' (thereby confirming Vicky Randall's view mentioned earlier). As a consequence quotas can be rendered pointless if there are insufficient women who are willing to stand, which is often the case at local council level. This in turn reduces the number of politically experienced female candidates at Land and federal level. ${ }^{37}$

Another problem for some women who combine political careers with raising a family is disapproval from colleagues, especially other women. They are criticised for missing political engagements due to family obligations, and seen to be neglecting their children if they attend everything. ${ }^{38}$ Furthermore, one female candidate recalls constantly being asked how she would cope with her responsibilities as an MP and a mother, while few questions were asked about her political views and policies. ${ }^{39}$ Although problems achieving an equitable work-life balance may also affect male MPs with young families, it appears that different standards apply, based on the assumption that their wives are at home looking after the children. In contrast, examples of female MPs with husbands who forego their careers to look after the family are rare. One example is former federal minister, Renate Schmidt, but Kolinsky argues that this role reversal is more conservative than radical, as it essentially accepts that career and family cannot be combined. ${ }^{40}$ In general women MPs interviewed by the author felt a great deal of pressure to prove that women with young children can and should be MPs, not only to prove their critics wrong, but also to encourage other young women to stand for political office.

\section{POLITICAL PARTIES' POLICIES TO PROMOTE WOMEN AND THEIR IMPACT}

Almost all of the political parties represented in the Bundestag claim to be committed to ensuring that women are fairly represented among their ranks. This section outlines the organisational mechanisms employed by the main parties to achieve this, notably 
women's quotas, and considers whether 'the socio-environmental preconditions for political participation’ are taken into account.

Alliance 90/the Greens were the pioneers of women's quotas in Germany in the 1980s and their Frauenstatut requires that party lists for elections are compiled using the 'zipping' method, with women occupying the odd-numbered positions, men the even numbered ones. The parity principle also applies elsewhere within the party, for example for conference delegates, party workers and other office holders such as chairs and speakers, often leading to the creation of joint posts. While quotas are the primary means of ensuring women are at least as well represented as men within the Greens, some practical measures have also been introduced to encourage equal opportunities, notably the right to childcare at party events and to financial assistance towards childcare which is enshrined in the Frauenstatut, ${ }^{41}$ But are these measures sufficient to guarantee genuine equal representation of both sexes within the Greens and to banish sexism from the party's culture? Although in quantitative terms this seems to be the case, with over 50 per cent of Green MPs at federal and Land level being women, there is evidence to suggest that women still face certain obstacles and that without quotas equality would not be guaranteed, since even within the Greens men are prone to 'gender specific behaviour' which works against true equality. ${ }^{42}$ The clearest indication of this is that when it comes to choosing constituency candidates to fight for direct mandates the majority are male, ${ }^{43}$ but in practice this matters little because the Greens have only ever won one of these at federal level. ${ }^{44}$ In the end, although the Greens are committed to gender equality, some of their practices are not dissimilar to those in other parties, particularly when it comes to the day-to-day functioning of politics, and this impacts on those with family responsibilities. In the words of one female MP, 'political decisions are made behind closed doors, in non-transparent circles; whoever isn't there in the evenings quickly becomes an outsider and plays no role within their party'. Furthermore, 'even in the Greens, missing things due to childcare problems and limited participation aren't accepted'. 45

The Social Democratic Party (SPD) also relies on a formal quota to improve the position of women in the party. Since 1994 the quota (Mindestabsicherung) has been 40 per cent and applies to men and women, neither of whom may occupy over 60 per cent of 
positions. However this level is yet to be achieved in the Bundestagsfraktion since it is hard to enforce in the case of direct mandates. At the 2005 federal election 104 of the party's constituency candidates were women (34.8 per cent). Furthermore compliance with the quota at Land level has been very mixed. ${ }^{46}$ For several years the SPD's organisation for women, the Arbeitsgemeinschaft Sozialdemokratischer Frauen (ASF), has been dissatisfied with the quota of 40 per cent as it tends to put a cap on the number of women on party lists and other bodies, and as such works against the long-term goal of parity. ${ }^{47}$ The ASF is also sceptical about the ability of a quota system to create genuine equality within the party without other changes to party practices and culture which are shaped by male norms of behaviour. ${ }^{48}$ In its most recent report on equality within the party several strategies were proposed to improve the situation, including a mentoring scheme for young women and a membership drive aimed at increasing the number of female party members. ${ }^{49}$ However there is no mention of other practical measures which might encourage more women to stand. In contrast, a working party on equal opportunities at the SPD's party headquarters initiated the introduction of a new agreement to help employees combine their careers with family life which gives parents the right to work from home, with the aim of making it easier for women to continue their jobs after childbirth and reducing the need for a career break. ${ }^{50}$ However at present this entitlement does not apply to politicians.

Like the Greens the Left Party operates a formal women's quota of 50 per cent which is enshrined in the party statute, and the same 'zipping' principle is applied to party lists. Parity in other forums is also a requirement, including the party executive, conferences and among staff. These policies had been implemented by the PDS for many years, before the official merger with the Wahlalternative Arbeit und soziale Gerechtigkeit (WASG) to form the new Left Party in 2007. However, at the time of the 2005 federal election the parties' electoral alliance was still unofficial and the WASG did not enforce the 50 per cent quota for its candidates. Consequently just under half of the first Left Party Bundestagsfraktion were women .

Prior to the merger the PDS had recognised that formal rules such as quotas were not sufficient to guarantee equality of opportunity within party structures. The party blamed patriarchal traditions, in particular, the gender specific division of labour in society for 
this, but was not itself entirely blameless. The need to transform 'inner-party culture' was recognised as far back as 1997 and a host of other measures to complement quotas were proposed, including making active politics more compatible with family life. ${ }^{51}$ In 2000 the Party Council blamed structures and working habits which still gave men an unfair advantage for the problems implementing quotas and other schemes designed to promote women. ${ }^{52}$ While the party took a more positive attitude towards families than others, allowing activists to bring children to party events for example, even in the PDS many key decisions were made late at night in male-dominated networks. ${ }^{53}$ The statute of the new Left Party commits it to provide free childcare at all federal party events and meetings, ${ }^{54}$ but it remains to be seen whether party branches at Land and local level will implement the policy, especially in the west, where the party's membership is male dominated. Overall, according to Gesine Lötzsch MdB, women still have a lot to do if the Left Party is to become a truly egalitarian party. ${ }^{55}$

In spite of its more traditional view of women's role in society the Christian Democratic Union (CDU) has addressed the issue of how to increase female representation among its ranks. Again, the primary means of achieving this is via a quota, known as the 'quorum resolution', adopted in 1996, with a target level of female representation of 33 per cent. The measure contributed to a rise in the number of CDU members of the Bundestag until 2002 but the current percentage is well below a third at 20.5 per cent. This is essentially because the quorum is only applied to party lists but not candidates for direct mandates. ${ }^{56}$ It has also proved harder to impose at Land level than federal level, with traditional views regarding the role of women prevalent among many local party branches. ${ }^{57}$ In 2003 the party's annual conference acknowledged the need to change its working practices, recognising that women have to juggle their family lives, careers and voluntary work, ${ }^{58}$ but few concrete measures have been introduced to complement the 'quorum resolution', apart from childcare at some party events. Furthermore, while the party may have become somewhat more accepting of women as politicians and mothers, this only applies to married women. Katherina Reiche $\mathrm{MdB}$ admits to having come under 'enormous pressure' to marry from the party machine when she was an unmarried mother. ${ }^{59}$

The CDU's sister party, the Christian Social Union (CSU) has no formal measures designed to increase its female MPs, let alone schemes to help women take up the 
opportunities available. The chair of the parliamentary party in Bavaria claims that the choice of Angela Merkel as chancellor candidate indicated that in the CDU/CSU the best

person wins, without the need for quotas. ${ }^{60}$ Currently 17.4 per cent of CSU Bundestag members are women, with a similar proportion in the Bavarian Landtag, and it seems unlikely that any measures to increase the proportion of female CSU politicians will be introduced for the foreseeable future.

The liberal Free Democratic Party (FDP) pays lip service to the objective of increasing the proportion of women among its ranks but even the Federal Union of Liberal Women rejects the implementation of quotas. Over the past decade there has been much talk about increasing women's opportunities within the party ${ }^{61}$ but few concrete initiatives. As is the case in all the parties, MPs are expected to undertake many duties out of hours which is problematic for female MPs in particular, as one states: 'It's hard to demonstrate enough presence in the party with family responsibilities' ${ }^{62}$ Even so, the proportion of female MPs in the Bundestag Fraktion is slowly rising (currently around a quarter) but this figure is still too low to have much impact on party culture and practices.

\section{COMMON PROBLEMS AND POTENTIAL SOLUTIONS}

This article has highlighted some of the problems encountered by women MPs in Germany and anticipated by potential women candidates, which quotas alone cannot resolve. Perhaps surprising is the similarity of experience among women of different political parties. Many of these problems are faced by nearly all female politicians, but less so those who are more able to act like their male counterparts and to fit in with the prevailing party culture. It has become apparent from this research that one of the biggest challenges for women is how to penetrate the male-dominated networks where key decisions are made, often after hours in social settings. Linked to this is a second problem, namely the number of events in the evenings and at weekends which one must attend in order to develop a high profile, not to mention the honorary positions one must take on in order to stand a chance of securing a nomination or leadership position. While women's quotas have made a difference, they help little when it comes to the selection of constituency candidates and do not necessarily guarantee the most promising list places 
for women if the zipping principle is not used. A third problem for many women is more psychological. Some women fear that if they try to combine a political career with raising a family they may fail, thereby proving right the sceptics who believe that mothers should stay at home with their children and not have careers, least of all in politics. As a consequence many women decline the opportunity to stand for office, which can result in quotas being unfulfilled.

Accepting that quotas alone do not create equal opportunities in politics, what other measures might help? This research suggests that only the gradual transformation of party cultures that give men inbuilt advantages will make a difference. This is more likely to occur in parties where a 'critical mass' of women has been reached. In the mean time contributors to this study saw the need for women to cooperate more with each other and to create support networks of their own. Generally however, most female politicians with family obligations have to find their own solutions in order to be able to compete with their peers, relying on spouses and grandparents, private full-time childcare, and high levels of personal organisation. As this research has found, most find little consideration of their circumstances is made, especially in the mainstream parties.

Female MPs themselves have a few suggestions that would make the conduct of politics more family-friendly, including a reduction in the number of weekend and evening engagements, and a more reliable and efficient parliamentary timetable with fewer 'ritualised speeches that serve the self-image of the (mainly male) speakers and waste a lot of time'. ${ }^{63}$ However some believe the only solution is for German society to become more egalitarian and family-friendly. At the end of the day, for many female politicians a choice has to be made: either to decide against having a family in order to devote themselves to their chosen career, or to enter politics later, which may have an impact on their career progression. The evidence suggests that some women choose the former option, others the latter. Most of the parliamentarians interviewed for this study claimed to know female colleagues who had indefinitely postponed starting a family for the good of their careers and records of party service. Meanwhile differences in the age profiles of male and female Bundestag members, with relatively few women in the youngest age groups, suggest that women enter politics later, either through choice or necessity ${ }^{64}$ 


\section{CONCLUSION}

The findings of this research suggest that while not impossible, combining a political career with family life is an additional challenge for many women politicians, on top of all the other hurdles they have to overcome, such as discrimination and exclusion from male-dominated networks. Indeed, as Phillips suggested, who collects the children and makes the tea is still a political concern. While some women do manage to break through the so-called 'glass ceiling', others are confronted by a 'maternal wall' which necessitates difficult choices which are not faced by their male counterparts and may even deter them from standing in the first place. Those women who do successfully combine child-rearing with a political career, such as Ursula von der Leyen, seem to do so against the odds, assisted by particularly supportive husbands or partners, nannies and housekeepers, exceptional hard work and determination, and in some cases, a wealthy background. However, even von der Leyen has been accused of being a bad mother and her personal circumstances initially attracted more media attention than her policies, ${ }^{65}$ which would have been be unlikely, had she been a male minister with a large family. However, like the former British Prime Minister Margaret Thatcher, von der Leyen would appear to be an exceptional case.

For many female politicians, two factors conspire to make it hard for them to experience the same career opportunities as their male colleagues: firstly, the prevalence of traditional gender-specific roles in the home and in society at large; and secondly, the lack of effort by parties and policy makers to make parliamentary practices more compatible with family life. However this does not mean that the desire for a more equitable work-life balance is an issue for female MPs alone. As mentioned earlier, gender mainstreaming means considering the effects of policies and practices on both women and men, and more consideration of work-life balance issues could also benefit male MPs with young families.

There is clearly scope for further research into the issues raised in this article, for example, into the functioning of politics at Land level to see if a more equitable work-life balance is possible, thus making a political career at sub-national level a more realistic option for many women. However Louise K. Davidson-Schmich’s article in this volume 
suggests that this is not the case, largely due to the fact that quotas have not altered the hierarchical and competitive nature of German politics which is unappealing to many women. Comparisons with the practicalities of political life in other countries would also be beneficial, especially those with higher than average levels of women in legislatures, for example, the Scandinavian nations. While the representation of women in German politics has improved greatly since Kolinsky’s studies in the early 1990s, largely due to the introduction of quotas, these measures alone have not totally transformed the practices or the culture of German politics. Consequently, especially for women with 'multiple commitments' 'the socio-environmental preconditions for political participation' are yet to be created.

\section{NOTES}

\footnotetext{
${ }^{1}$ The author wishes to acknowledge the support of the Anglo-German Foundation for the Study of Industrial Society for this project.

${ }^{2}$ Eva Kolinsky, Women in Contemporary Germany. Life, Work, Politics (Oxford: Berg, 1993); Eva Kolinsky, Women in 20 ${ }^{\text {th }}$ Century Germay: a Reader (Manchester: Manchester University Press, 1995).

${ }^{3}$ Eva Kolinsky and Hildegard Maria Nickel, (eds), Reinventing Gender: Women in Eastern Germany since Unification (London: Frank Cass, 2003).

${ }^{4}$ Eva Kolinsky, 'Party Change and Women's Representation in Unified Germany', in Joni Lovenduski and Pippa Norris (eds), Gender and Party Politics (London: Sage, 1993), pp.113-46; Kolinsky, Women in Contemporary Germany, pp.192-293.

${ }^{5}$ Eva Kolinsky, 'Political participation and parliamentary careers: Women’s Quotas in West Germany', West European Politics 14/1 (1991), pp.56-72.

${ }^{6}$ Kolinsky, 'Party Change and Women's Representation', p.146.

${ }^{7}$ Kolinsky, Women in Contemporary Germany, p.290.

${ }^{8}$ For a general discussion of female representation in German politics in recent years see Joanna McKay, 'Women in German Politics: Still Jobs for the Boys?' German Politics 13/1 (2004), pp.56-80.; Joyce Marie Mushaben, '”Girl Power”: Women, Politics and Leadership in the Berlin Republic' in James Sperling (ed), Germany at Fifty-five. Berlin ist nicht Bonn? (Manchester: Manchester University Press, 2004), pp.183-91.

${ }^{9}$ See Mark R. Thompson and Ludmilla Lennartz, 'The Making of Chancellor Merkel', German Politics 15/1 (2006), pp.105-07.

${ }^{10}$ Kolinsky, 'Political participation', p.69.

${ }^{11}$ Kolinsky, 'Political participation', pp.69-70.

12 Kolinsky, Women in Contemporary Germany, p.253.

13 'Die Unmögliche', Der Tagesspiegel, 20 March 2006. The term was allegedly used by Renate Künast of the Greens.

${ }^{14}$ Vicky Randall, Women and Politics: an International Perspective, $2^{\text {nd }}$ ed. (Basingstoke: Macmillan, 1987), p.323
} 


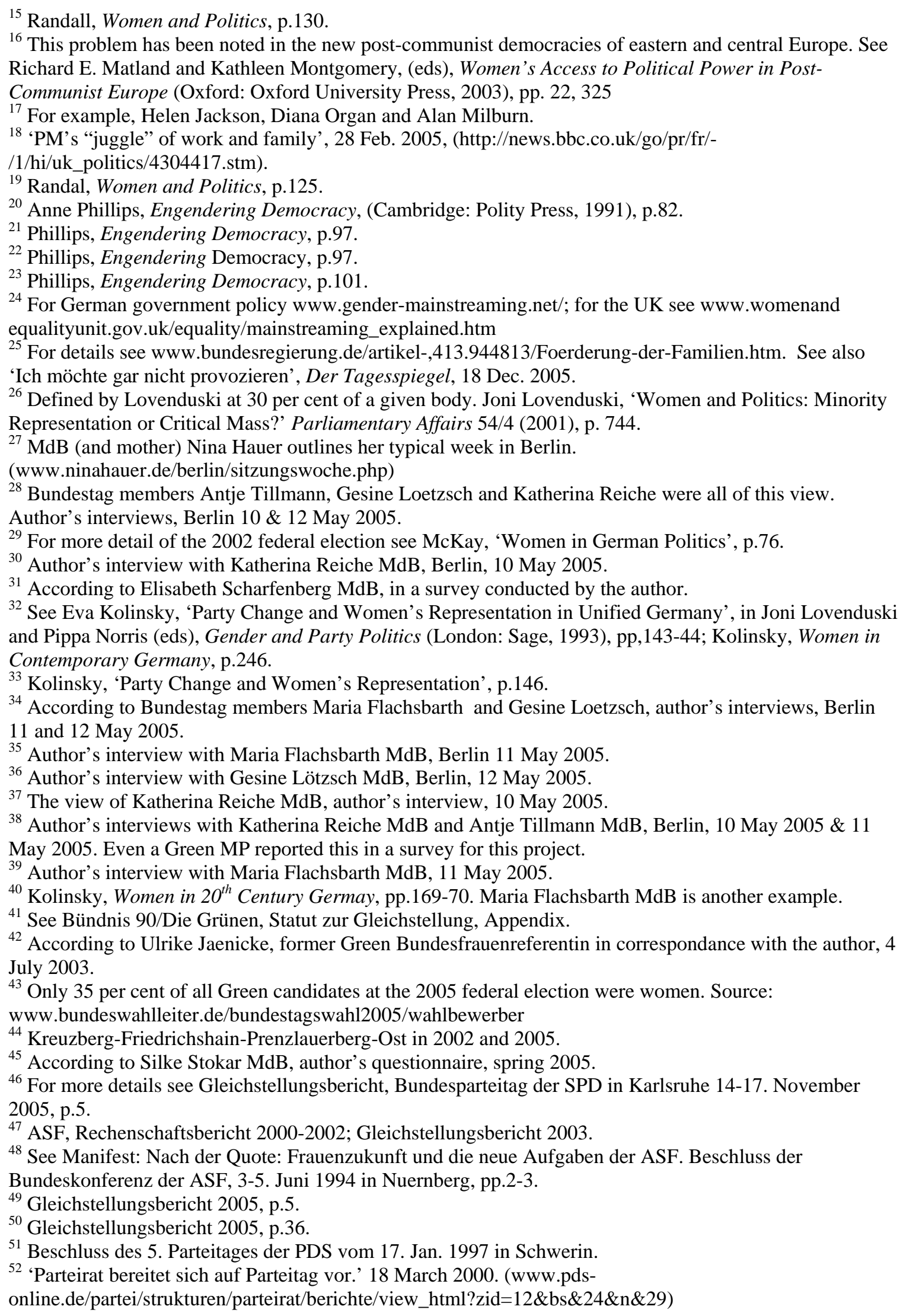


${ }^{53}$ According to Gesine Lötzsch MdB, author’s interview, Berlin, 12 May 2005.

${ }^{54}$ Bundessatzung der Partei Die Linke, http://sozialisten.de/sozialisten/parteibildung/gruendungsdokumente/view_html?zid=34759\&bs=1\&n=3

${ }_{55}$ Author’s interview, Berlin, 12 May 2005.

${ }^{56}$ While 30 per cent of CDU MPs elected via lists are female, only 14 per cent of those elected for direct mandates are women.

${ }^{57}$ Frauenbericht der CDU Deutschlands 2004 (www.frauenunion.de/content/blogcategory/22/67/)

${ }^{58}$ Frauenbericht der CDU Deutschlands 2004 p.2. (www.frauenunion.de/content/blogcategory/22/67/)

${ }^{59}$ Author's interview, 9 May 2005

${ }^{60}$ Joachim Herrmann, 'CDU und CSU sind die eigentlichen Frauenparteien', 6 June 2005.

(www.csu.de/Gremien/Display/ag_aktuelles?verband=ag_Fu\&reiter=reiter1)

${ }^{61}$ See McKay, 'Women in German Politics', pp.72-3.

${ }^{62}$ According to Christel Happach-Kasan MdB, author's survey, spring 2005.

${ }^{63}$ According to Silke Stokar MdB, author's survey, spring 2005.

${ }^{64}$ Of 57 MPs born after 1970 only 15 are women. Source: Kürschners Volkshandbuch Deutscher Bundestag 16. Wahlperiode (Rheinbreitbach:NDV, 2006), p.291.

${ }^{65}$ See 'Die Unmögliche', Der Tagesspiegel, 20 March 2006; 'Super Mama', Der Tagesspiegel, 11 Feb. 2006; 'Gesucht: Haus für Familie mit sieben Kindern’, Der Tagesspiegel, 10 Nov. 2005. 